九州大学学術情報リポジトリ

Kyushu University Institutional Repository

Host Discrimination and Factors Affecting

Incidence of Superparasitism in Hemiptarsenus

varicornis (Hymenoptera: Eulophidae), a

Parasitoid of the Leafminer Liriomyza trifolii

(Diptera: Agromyzidae)

Ho, Thi Thu Giang

Department of Entomology, Faculty of Agronomy, Hanoi University of Agricultural

Ueno, Takatoshi

Institute of Biological Control, Faculty of Agriculture, Kyushu University

https://doi.org/10.5109/12856

出版情報：九州大学大学院農学研究院紀要. 53 (2)，pp.447-452，2008-10-28. Faculty of Agriculture, Kyushu University

バージョン：

権利関係 : 


\title{
Host Discrimination and Factors Affecting Incidence of Superparasitism in Hemiptarsenus varicornis (Hymenoptera: Eulophidae), a Parasitoid of the Leafminer Liriomyza trifolii (Diptera: Agromyzidae)
}

\section{Thi Thu Giang $\mathrm{HO}^{1}$ and Takatoshi UENO ${ }^{2 *}$}

\author{
${ }^{1}$ Department of Entomology, Faculty of Agronomy, Hanoi University of Agricultural, \\ Trau Quy, Gia Lam, Ha Noi, Vietnam \\ ${ }^{2}$ Institute of Biological Control, Faculty of Agriculture, Kyushu University, \\ Fukuoka 812-8581, Japan \\ (Received June 27, 2008 and accepted July 16, 2008)
}

\begin{abstract}
An ovipositing parasitoid can save searching time, energy and eggs by avoiding superparasitism, and superparasitism avoidance hence is a factor that affects searching efficiency of a parasitoid. This study examined host discrimination and environmental factors causing superparasitism in the solitary parasitoid wasp Hemiptarsenus varicornis, a promising candidate for biological control of dipteran leafminers such as Liriomyza trifolii and L. sativae. Cage experiments showed that the pattern of parasitoid egg distributions among hosts skewed significantly from the Poisson distribution. This suggested that $H$. varicomis had the host-discrimination ability. However, superparasitism avoidance was not perfect; hosts that had received two parasitoid eggs were observed. Accordingly, factors affecting the incidence of superparasitism were examined. Superparasitism was observed only for third host larval instars, the most suitable host stage for parasitoid development. Superparasitism occurred more frequently when females laid more eggs, suggesting that females with a greater motivation to oviposit were more likely to superparasitize. The level of superparasitism also increased when fewer numbers of third host instars were available for females. The number of second instars of $L$. trifolii available did not affect superparasitism incidence on third host instars. Host discrimination and superparasitism in H. varicornis are discussed in terms of its searching efficiency and mass-rearing procedure.
\end{abstract}

\section{INTRODUCTION}

Leafminer insects such as Liriomyza trifolii (Burgess) and L. sativae Blanchard (Diptera: Agromyzidae) cause serious damage to many agricultural crops (e.g., Levins et al., 1975; Schuster et al., 1976; Minkenberg and van Lenteren, 1986; Parrella, 1987; Spencer, 1989; Rauf et al., 2000; Tran et al., 2007a). Because they have developed insecticide resistance (e.g., Parrella et al., 1984; Mason et al., 1989; Saito et al., 1992; Ohno et al., 1999a, b), dipteran leafminers are often difficult to control exclusively with chemicals. Therefore, research has been conducted to test various IPM strategies and combinations of different control methods against pest leafminers (e.g., Trumble, 1985; Minkenberg and van Lenteren, 1986, 1987; Heinz and Parella, 1993; Weintraub and Horowitz, 1998; Ohno et al., 1999a; Ozawa et al., 1999, 2001; Weintraub, 2001).

Parasitoid wasps are shown to suppress dipteran leafminers in greenhouses throughout Europe, Japan and North America; two commercialized parasitoid species, Diglyphus isaea (Walker) (Eulophidae) and Dacnusa sibirica Telenga (Braconidae), are commonly used as control agents (Wardlow, 1985; Minkenberg and van Lenteren, 1986, 1987; Saito et al., 1995; Ozawa et al., 1999, 2001). Also, in North America, the eulophid parasitoid Diglyphus begini (Ashmead) can successfully control L. trifolii (Heinz and Parella, 1990; Heinz et al., 1993).

More recently, Hemiptarsenus varicomis (Girault)

* Corresponding author (E-mail: ueno@grt.kyushu-u.ac.jp) has discovered as a major parasitoid of L. trifolii in Japan (Saito et al., 1996, 1997; Arakaki and Kinjo, 1998; Ozawa et al., 2001; Ohno et al., 1999b). H. varicomis is in the Eulophidae family and is native to Japan, Indonesia, and probably to other part of East and SouthEast Asia (Konishi, 1999). This parasitoid increases its population in greenhouses and can become predominant over $D$. isaea and $D$. sibirica, which have been released to control L. trifolii (Ozawa et al., 2001). Parasitism of L. trifolii by $H$. varicornis is also high in subtropical regions (Arakaki and Kinjo, 1998; Rauf et al., 2000). Thus, the parasitoid is a promising agent for controlling pest leafminers.

$H$. varicornis flies or hops from leaf to leaf where host leafminers can be present. On the leaf, the parasitoid walks and drums the leaf with its antennae to search and feel for leafminer larva on the leaf. Once it encounters a mine in the leaf, it starts to search along with the mine, mostly in the direction to which the target hsot larva is present (Ayabe and Ueno, 2004). The adult wasps that emerge feed on leafminer larvae for host feeding (Ho and Ueno, 2002, 2007). H. varicornis develops mainly in the second and third instars of the leafminers (Bordat et al., 1995).

Relatively few studies have investigated the life history and biology of $H$. varicomis. Many biological parameters that are required to assess as a biocontrol agent still have poorly been known. Host discrimination and superparasitism are among such biological characteristics. Accordingly, the present study focuses on host discrimination and superparasitism in H. varicornis.

Superparasitism refers to parasitization of an indi- 
vidual host by more larvae of a single parasitoid species than can mature on that host individual (van Alphen and Visser, 1990; Godfray, 1994; Ueno, 1997, 1999a; Dorn and Beckage, 2007). For solitary parasitoids, in which only one parasitoid can develop to an adulthood on a single host individual, superparasitism takes place when more than one egg are laid on a single host individual. A single female individual or a succession of females of the same species may lay eggs on a host that has been previously parasitized. Superparasitism results in a waste of eggs through lethal competition among parasitoid larvae (e.g., Harvey et al., 1993; Godfray, 1994; Ueno, 1997; Dorn and Beckage, 2007). In some cases, superparasitism causes direct mortality of hosts, leading also to a waste of parasitoid progeny (Ueno, 1997). Thus, the production efficiency of parasitoids for biological control should decrease when superparasitism occurs frequently in laboratory rearing systems. To produce biological control agents efficiently, we need the knowledge of laboratory environments in which the incidence of superparasitism can be minimized.

Avoidance of superparasitism is also important for parasitoids to be an efficient forager. Superparasitism avoidance is attained by avoiding parasitized hosts directly or by avoiding areas where parasitized hosts are present. Host discrimination, an ability of an ovipositing parasitoid to discriminate between parasitized and unparasitized hosts, is a general mechanism by which parasitoids avoid superparasitism (van Lenteren, 1981; Hofsvang, 1990; Godfray, 1994). Therefore, investigation of host discrimination and superparasitism avoidance in a parasitoid will help uncover to assess whether it can be an efficient forager, or a potentially effective biocontrol agent.

The purpose of the present study is to evaluate the host discrimination ability in $H$. varicornis and to examine factors influencing superparasitism avoidance in this parasitoid. Knowing factors that deter superparasitism avoidance in $H$. varicornis will help assess environmental conditions in which the parasitization efficiency can be disruptive. This information will help improve massrearing systems of $H$. varicornis.

\section{MATERIALS AND METHODS}

\section{Parasitoids and hosts}

Culture of host leafminer Liriomyza trifolii was maintained using Kidney bean plants. The parasitoid Hemiptarsenus varicornis were reared on larvae of the leafminer. General methods for rearing L. trifolii and $H$. varicornis are described by Ho and Ueno (2002, 2007).

\section{Cage experiment}

Kidney bean plants infested with large numbers of $2^{\text {nd }}$ and $3^{\text {rd }}$ instars of L. trifolii were used in this experiment. Potted plants with leafminers were individually placed in a transpearent plastic box $(20 \mathrm{~cm} * 20 \mathrm{~cm} * 35 \mathrm{~cm})$ and then one female $H$. varicornis was carefully introduced into the box. Tissue paper saturated with diluted honey (20\%) was also placed in the box to provide female parasitoids with food.

Female $H$. varicornis were allowed to attack leafminers for 24 hours. After a $24 \mathrm{~h}$ exposure, plants were removed from the cage, and leafminers within leaf tissues were checked under a binocular stereoscopic microscope. For each leafminer, the larval instar $\left(2^{\text {nd }}\right.$ or $3^{\text {rd }}$ instars) was noted and the number of parasitoid eggs on the leafminer was recorded. When a single leafminer larva received more than two parasitoid eggs, then it was regarded that superparasitism took place on that larva.

This treatment was repeated for 5 consecutive days for each female parasitoid; thus a total of 5 plants with leafminers were given (female age: $1-5$ days). The experiment was conducted at $25 \pm 1{ }^{\circ} \mathrm{C}$ under a constant light. In all, 14 females of $H$. varicornis were used in the experiment.

\section{Data analyses}

Statistical treatments were made with the aid of JMP (SAS Institute, 2001). Because many test females attacked few hosts in the first and second days of the experimental period, data taken between the third and fifth days (female age: 3-5 days old) were used in the following analyses. Superparasitism avoidance was examined using chi-squared test, with which comparison was made between parasitoid egg distributions among hosts and expected distributions in case no discrimination took place. Expected egg distributions were calculated on the basis of the Poisson distribution, in which it was assumed that (1) parasitoids encountered hosts at random; (2) parasitoids might lay one egg or might avoid superparasitism upon encoutering with a parasitized host; and (3) the probability of avoidance was independent of the number of parasitoid eggs already present on the host. Data obtained during the experiment for 3 days were pooled for each test female parasitoid, and the analysis was made for each female parasitoid.

Factors causing superparasitism were then examined. Stepwise methods were first used to pick up significant parameters, and a multiple regression model was then obtained. Leverage plots were used to show the relationships between incidence of superparasitism and a given factor being significant. The percentages of superparasitism incidence calculated for each test female were used as a dependent variable and were subject to the analyses after arcsine square root transformation. Three factors, i.e., the numbers of $2^{\text {nd }}$ and $3^{\text {rd }}$ host instars given for each female and the total number of eggs laid by the female, were evaluated as independent variables. Non transformed data were reported.

\section{RESULTS}

Superparasitism by $H$. varicornis was observed in our laboratory test though the level of superparasitism was generally very low. Because female $H$. varicornis strongly preferred $3^{\text {rd }}$ over $2^{\text {nd }}$ host instars of L. trifolii for oviposition and because no superparasitism was observed for the $2^{\text {nd }}$ larval instars, data were analyzed only for $3^{\text {rd }}$ instars. The percentages of superparasitism 
incidence (superparasitized $3^{\text {rd }}$ host instars/parasitized host $3^{\text {rd }}$ instars*100) varied among test females, ranging from $0 \%$ to $40.0 \%$ (Table 1). The mean percentage of hosts (with $\pm \mathrm{SE}$ ) that had received multiple parasitoid eggs was $7.38 \pm 2.66 \%$.

The presence of host discrimination was evaluated by examining patterns of egg distributions. Egg distributions were significantly different from Poisson distributions for data from 7 out of 14 test females (Table 1). Overall, the number of hosts receiving multiple eggs (=superparasitized hosts) was much fewer than that expected from random egg distributions. In fact, the numbers of superparasitized hosts observed were fewer than the expected numbers of superparasitized hosts from Poisson distributions (Fig. 1). The results of our experiments strongly suggested that $H$. varicornis had the host-discrimination ability.

The relationships among three independent variables, i.e., the numbers of $2^{\text {nd }}$ and $3^{\text {rd }}$ host instars given for

Table 1. Incidence of superparasitism in Hemiptarsenus varicornis

\begin{tabular}{rrcll}
\hline $\begin{array}{c}\text { Wasp } \\
\text { no. }\end{array}$ & $\begin{array}{r}\text { Total } \\
\text { hosts }\end{array}$ & $\begin{array}{c}\% \\
\text { superparasitism }\end{array}$ & $\begin{array}{c}x^{2} \\
\text { values* }\end{array}$ & $P$ values \\
\hline 1 & 106 & 17.65 & 2.98 & 0.084 \\
2 & 83 & 0 & 6.90 & $0.009^{* *}$ \\
3 & 59 & 40.0 & 0.36 & 0.55 \\
4 & 123 & 7.69 & 0.13 & 0.71 \\
5 & 180 & 0 & 2.48 & 0.12 \\
6 & 184 & 0 & 6.63 & $0.010^{* *}$ \\
7 & 141 & 5.41 & 4.44 & $0.035^{* *}$ \\
8 & 225 & 2.78 & 5.99 & $0.014^{* *}$ \\
9 & 106 & 4.76 & 0.40 & 0.53 \\
10 & 176 & 3.45 & 2.39 & 0.12 \\
11 & 58 & 0 & 3.84 & $0.049 * *$ \\
12 & 144 & 3.23 & 3.46 & 0.063 \\
13 & 116 & 12.82 & 5.62 & $0.018^{* *}$ \\
14 & 266 & 0 & 9.38 & $0.002^{* *}$ \\
& & & & \\
\hline
\end{tabular}

* Chi-squared values represent divergence from the Poisson distribution.

** $P$ values that are significant.

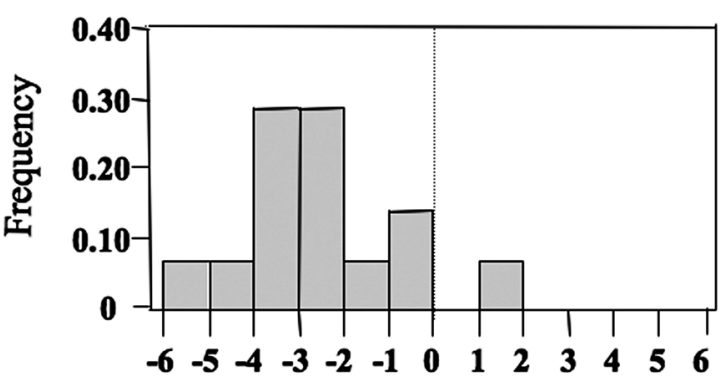

Difference from expected numbers of hosts superparasitized

Fig. 1. The remainders of subtracting the expected from the actual numbers of superparasitized hosts. The majority of the values are below zero, suggesting the tendency of female H. varicornis avoiding superparasitism. each female and the total number of eggs laid by the female, were examined. No significant correlations were detected. Stepwise regression analysis was then made to select factors affecting the levels of superparasitism. The number of $2^{\text {nd }}$ instars given to each test female was not significant and was excluded from the following model. A multiple regression analysis was made with the remaining two factors to determine the relationships between the two and superparasitism. The model obtained was significant $\left(r^{2}=0.542, \mathrm{~N}=14, \quad F=6.499\right.$, $P=0.014$ ), and the number of host $3^{\text {rd }}$ instars given and the number of eggs laid were both found significant (Table 2). The interaction between the two factors was not significant and was not included in the model. Leverage plots showed a negative relationship between superparasitism and the number of $3^{\text {rd }}$ host instars given (Fig. 2a) while a positive relationship was detected

Table 2. The result of multiple regression analysis for factors affecting the level of superparasitism

\begin{tabular}{crc}
\hline Factors & $t$ values & $P$ values \\
\hline \# eggs laid & 2.22 & 0.053 \\
\# $3^{\text {rd }}$ instars & -2.80 & 0.005 \\
\hline
\end{tabular}

Whole model: $r^{2}=0.542, \mathrm{~N}=14, F=6.499, P=0.014$.

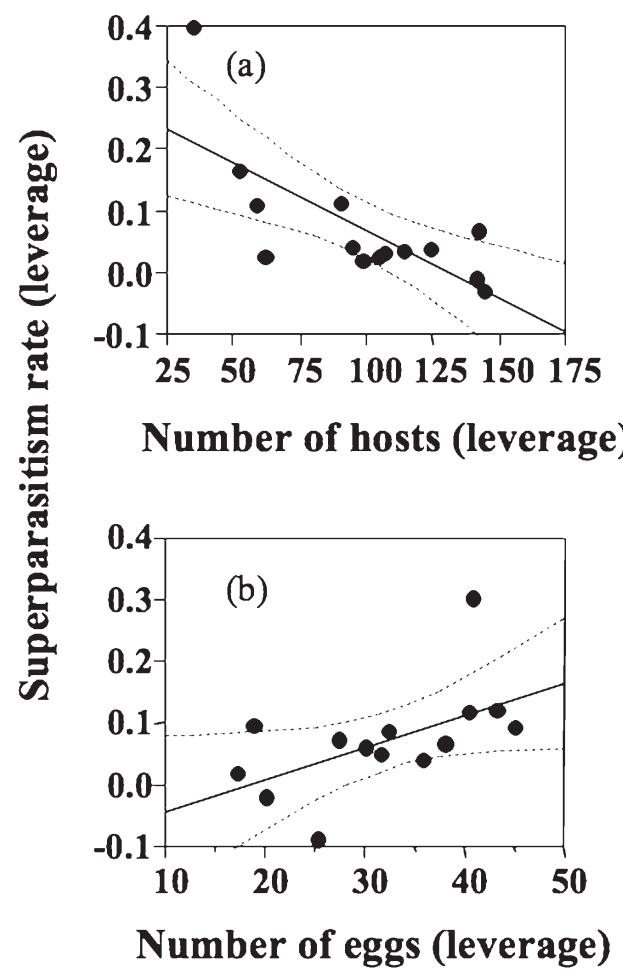

Fig. 2. Leverage plots for testing whether the two factors included in the multiple regression model (see Table 2.) significantly correlate to the rate of superparasitism observed. (a) The relationship with the total number of eggs laid by female parasitoids and (b) that of hosts given to them during a 3 day experimental period. Dotted lines show $95 \%$ confidence curves. Statistical results are given in Table 2. 
between superparasitism and the number of eggs laid during the experiment (Fig. 2b). Thus, when suitable hosts, $3^{\text {rd }}$ larval instars of $L$. trifolii, were few, female $H$. varicornis commit superparasitism. Also, females that carried and laid more eggs were more likely to superparasitize.

\section{DISCUSSION}

\section{Superparasitism Avoidance}

An indigenous larval parasitoid, $H$. varicomis, appears to be effective in controlling dipteran leafminers (Ozawa et al., 2001). Part of the reasons would be that $H$. varicornis is an efficient forager. Having a high ability of avoiding superparasitism may be a behavioral mechanism of being an efficient forager because superparasitism avoidance allows a foraging female to save time, energy and eggs (van Alphen and Visser, 1990; Weisser and Houston, 1993). Thus, the presence of a strong tendency to avoid superparasitism may partly explain why $H$. varicornis is an effective parasitoid.

The present paper demonstrates that $H$. varicornis is capable of avoiding superparasitism. The mechanisms by which $H$. varicornis avoids superparasitism are not known. Many literatures have given evidence that an ovipositing parasitoid deposits chemical markers on or in a host (host-marking pheromones), which allows it or females subsequently encounter that host to recognize prior parasitism (van Lenteren, 1981; Hofsvang, 1990; Godfray, 1994). Female parasitoids can thereby discriminate between parasitized and unparasitized hosts. The presence of such marking pheromones is not examined for $H$. varicornis. However, some parasitoids attacking dipteran leafminers do use marking pheromones to avoid a previously parasitized host and/or a previously searched area (Sugimoto et al., 1986). It is likely that $H$. varicornis uses a similar system. Future research will uncover this point.

\section{Factors causing superparasitism}

Although $H$. varicornis had the host discrimination ability, discrimination was not always perfect; superparasitism did occur in the present study. For many parasitoids, superparasitism has frequently been observed in the laboratory (van Lenteren, 1981; van Alphen and Visser, 1990; Ueno, 1999a). There are a number of explanations why superparasitism does take place (van Alphen and Visser, 1990; Weisser and Houston, 1993). A major factor is host density; when there are a limited number of hosts, female parasitoids begin to commit superparasitism (van Lenteren, 1981). This was the case for $H$. varicronis. When $3^{\text {rd }}$ instars of leafminers were fewer, the number of hosts that were superparasitized increased significantly. However, the number of second host instars did not influence the incidence of superparasitism. In our experimental set-up, H. varicornis parasitized mostly on $3^{\text {rd }}$ instars, and this is because they are most suitable for development of larval $H$. varicornis. Difference in host quality between $2^{\text {nd }}$ and $3^{\text {rd }}$ instars may explain why the number of less suitable, sec- ond instars do not affect superparasitism incidence.

Theory predicts that another factor causing superparasitism may be the level of females' motivation to oviposit (Fletcher et al., 1994; Ueno, 1999b). For example, female parasitoids with a greater number of mature eggs are more likely to accept low quality hosts including parasitized hosts (Fletcher et al., 1994). If this could be the case, the incidence of superparasitism would be greater for females that lay more eggs within a given period of time. To test this, the relationship between the number of eggs laid and the level of superparasitism was examined in our study. The results demonstrated a positive relationship between the two, supporting the idea that females with a greater oviposition potential are more likely to superparasitize.

\section{Mass-rearing of parasitoids}

Use of native parasitoids is an important approach in IPM of Liriomyza spp. in Japan and Vietnam (Ueno, 2006; Tran et al., 2007b). If native parasitoids are to mass-rear for release, then effective procedures of mass-rearing are required. Our study suggests that female $H$. varicornis can commit superparasitism in laboratory mass-rearing systems, particularly when ovipositional pressures are great and suitable $3^{\text {rd }}$ instars of hosts are scarce. When superparasitism occurs frequently, many parasitoid eggs should die before maturity because of lethal combat among parasitoid larvae hatched (van Lenteren, 1981). In addition, the quality of parasitized hosts can be lowered because of an increased parasitoid load, causing the production of lowquality parasitoids in terms of the size. The proportion of parasitized hosts that yield the offspring parasitoid can also decrease due to repeated attack of hosts (Harvey et al., 1993; Ueno, 1997; Dorn and Beckage, 2007).

Thus, the efficiency of parasitoid mass-rearing should be decreased if superparasitism could frequently take place. It is desirable to use rearing conditions in which the incidence of superparasitism is kept at minimum. The provision of sufficient numbers of suitable hosts, i.e., $3^{\text {rd }}$ instars of $L$. trifolii, is favorable in terms of reducing superparasitism. Basing on the data obtained in the present study, we suggest that at least around 30-40 leafminers of the $3^{\text {rd }}$ larval instars should be secured per female parasitoid together with $2^{\text {nd }}$ instars for host feeding when hosts are provided for females at a daily basis.

\section{ACKNOWLEDGEMENTS}

We thank Dr. K. Ogata at Institute of Tropical Agriculture, Kyushu University and Mrs. Y. Ayabe at Institute of Biological control, Kyushu University for their support and encouragement. We also thank Drs. A. Ozawa (Shizuoka Agricultural Experimental Station) and E. Yano (Kinki University) for their kind supply of $H$. varicornis, and Dr. K. Ohno (Miyazaki University) for his kind supply of $L$. trifolii. This work was partly supported by Grant-in-Aid from the Ministry of Education, 
Science, Sports and Culture of Japan (grant no. 15208007).

\section{REFERENCES}

Arakaki, N. and K. Kinjo 1998 Notes on the parasitoid fauna of the serpentine leafminer Liriomyza trifolii (Burgess) (Diptera: Agromyzidae) in Okinawa, southern Japan. Appl. Entomol. Zool., 33: 577-581

Ayabe, Y. and T. Ueno 2004 Directed search pattern of a leafminer parasitoid among mines of host larvae. Ann. Entomol. Soc. Am., 97: 586-591

Bordat, D., E. V. Coly and C. Roux-Olivera 1995 Morphometric, biological and behavioral differences between Hemiptarsenus varicornis (Hym., Eulophidae) and Opius dissitus (Hym., Braconidae) parasitoids of Liriomyza trifolii (Dip., Agromyzidae). J. Appl. Entomol., 119: 423-427

Dorn, S. and N. E. Beckage 2007 Superparasitism in gregarious hymenopteran parasitoids: ecological, behavioural and physiological perspectives. Physiol. Entomol., 32: 199-211

Fletcher, J. P., J. P. Hughes and I. F. Harvey 1994 Life expectancy and egg load affect oviposition decisions of a solitary parasitoid. Proc. Royal Soc. London B, 258: 163-167

Godfray, H. C. J. 1994 Parasitoids: Behavioral and Evolutionary Ecology. Princeton University Press, New Jersey

Harvey, J. A., I. F. Harvey and D. J. Thompson 1993 The effect of superparasitism on development of the solitary parasitoid wasp, Venturia canescens. Ecol. Entomol., 18: 203-208

Ho, T. T. G. and T. Ueno 2002 Biology of Hemiptarsenus varicornis (Hymenoptera: Eulophidae), a parasitoid wasp of the leafminer Liriomyza trifolii (Diptera: Agromyzidae). J. Fac. Agric., Kyushu Univ., 47: 45-54

Ho, T. T. G. and T. Ueno 2007 Improving parasitoid performance by improving adult food quality: a case study for the leafminer parasitoid Hemiptarsenus varicornis (Hymenoptera: Eulophidae). J. Fac. Agric., Kyushu Univ., 52: 57-61

Hofsvang, T. 1990 Discrimination between unparasitized and parasitized hosts in hymenopterous parasitoids. Acta Entomol. Bohemoslov., 87: 161-175

JMP 2001 JMP version 4.0. SAS Institute Inc., Cary, NC

Konishi, K. 1998 An illustrated key to the hymenopterous parasitoids of Liriomyza trifolii in Japan. Mis.s Pub. Nat. Inst. Agro-enviromental Sci., 22: 27-76 (In Japanese)

Heinz K. M. and M. P. Parrella 1990 Holarctic Distribution of the leafminer parasitoid Diglyphus begini (Hymenoptera: Eulophidae) and notes on its life history attacking Liriomyza trifolii (Diptera: Agromyzidae) in chrysanthemum. Ann. Entomol. Soc. Am., 83: 916-924

Heinz K. M., L. Nunney and M. P. Parrella 1993 Toward predictable biological control of Liriomyza trifolii (Diptera: Agromyzidae) infesting greenhouse cut chrysanthemums. Environ. Entomol., 22: 1217-1233

Minkenberg, O. P. J. M. and J. C. van Lenteren 1987 Evaluation of parasitic wasps for the biological control of leafminer, Liriomyza spp., in greenhouse tomatoes. IOBC/ WPRS Bulletin, 10: 116-120

Minkernberg, O. P. J. M and J. C. van Lenteren 1986 The leafminer Liriomyza bryoniae and L. trifolii (Diptera: Agromyzidae), their parasites and host plants: a review. Agric. U. Wagen. Pap., 86: $1-50$

Levins, R. A., S. L. Poe, R. C. Littell and J. P. Jones 1975 Effectiveness of a leafminer control program for Florida tomato production. J. Econ. Entomol., 68: 772-774

Mason, G. A., B. E. Tabashnik and M. W. Johnson 1989 Effects of biological and operational factors on evolution of insecticide resistance in Liriomyza (Diptera: Agromyzidae). J. Econ. Entomol., 82: 369-373

Ohno, K., K. Takesaki, D. Yamaguchi and H. Takemoto 1999a Effects of milbemectin acaricide on mortality rate of agromyzid leafminer, Liriomyza trifolii (Burgess), and its larval parasitoid, Diglyphus isaea (Walker) (Hymenoptera: Eulophidae).
Jap. J. Appl. Entomol. Zool., 43: 93-97

Ohno, K., T. Ohmori, and H. Takemoto 1999b Effect of insecticide applications and indigenous parasitoids on population trends of Liriomyza trifolii in gerbera greenhouses. Jap. J. Appl. Entomol. Zool., 43: 81-86

Ozawa, A., T. Saito and M. Ota 1999 Biological control of American serpentine leafminer, Liriomyza trifolii (Burgess), on tomato in greenhouses by parasitoids I. Evaluation of biological control by release of Diglyphus isaea (Walker) in experimental greenhouses. Jap. J. Appl. Entomol. Zool., 43 161-168

Ozawa, A., T. Saito and M. Ota 2001 Biological control of the American serpentine leafminer, Liriomyza trifolii (Burgess), on tomato in greenhousees by parasitoids II. Evaluation of biological control by Diglyphus isaea (Walker) and Dacnusa sibrica Telenga in commercial greenhouses. Jap. J. Appl. Entomol. Zool., 46: 61-74

Parrella, M. P. 1987 Biology of Liriomyza. Annu. Rev. Entomol., 32: 201-224

Parrella, M. P., C. B. Keil and J. G. Morse 1984 Insecticide resistance in Liriomyza trifolii. Calif. Agric., 38: 22-23

Rauf, A., B. M. Shepard and M. W. Johnson 2000 Leafminers in vegetables, ornamental plants amd weeds in Indonesia: Surveys of host crops, species composition and parasitoids. Int. J. Pest Manage., 46: 257-266

Saito T., A. Ozawa and F. Ikeda 1995 The evaluation of two imported hymenopteran parasites as biological control agents for the serpentine leafminer, Liriomyza trifolii (Burgess). Proc. Kanto Pl. Prot. Soc., 42: 235-237 (in Japanese)

Saito, T., F. Ikeda and A. Ozawa 1996 Effect of pesticides on parasitoid complex of serpentine leafminer Liriomyza trifolii (Burgess) in Shizuoka Preferecture. Jap. J. Appl. Entomol. Zool., 40: 127-133

Schuster, D. J., J. P. Jones and P. H. Everett 1976 Effect of leafminer control on tomato yield. Proc. Florida State Hort. Soc. 89: $154-156$

Spencer, K. A. 1989 Leafminer. In "Plant Protection and Quarantine Vol II. Selected Pests and Pathogens of Quarantine Significant", CRC Press, Inc., Boca Raton, Florida, USA, pp. $77-98$

Sugimoto, T., M. Uenishi and F. Machida 1986 Foraging for patchily distributed leaf-miners by the parasitoid, Dapsilarthra rufiventris (Hymenoptera: Braconidae). I. Discrimination of previously searched leaflets. Appl. Entomol. Zool. 21: 500-508

Tran, D. H., T. T. A Tran, L. P. Mai, T. Ueno and M. Takagi 2007a Seasonal abundance of Liriomyza sativae (Diptera: Agromyzidae) and its parasitoids on vegetables in southern Vietnam. J. Fac. Agric., Kyushu Univ., 52: 49-55

Tran, D. H., T. Ueno and M. Takagi 2007b Comparison of the suitability of Liriomyza chinensis and L. trifolii (Diptera: Agromyzidae) as hosts for Neochrysocharis okazakii (Hymenoptera: Eulophidae). Biol. Cont., 41: 354-360

Trumble, J. T. 1985 Integrated pest management of Liriomyza trifolii: Influence of avermectin, cyromazine, and methomyl on leafminer ecology in celery. Agric. Ecosys. Environ., 12: $181-188$

Ueno, T. 1997 Effects of superparasitism, larval competition, and host-feeding in the pupal parasitoid Pimpla nipponica (Hymenoptera.: Ichneumonidae) on offspring survival and fitness. Ann. Entomol. Soc. Am., 90: 682-688

Ueno, T. 1999a Behavioral evidence for recognition of parasitized hosts by superparasitizing Pimpla nipponica (Hymenoptera: Ichneumonidae). Can. J. Zool., 77: 413-417

Ueno, T. 1999b Host-feeding and acceptance by a parasitic wasp (Hymenoptera: Ichneumonidae) as influenced by egg load and experience in a patch. Evol. Ecol., 13: 33-44

Ueno, T. 2006 Current status of insects pests attacking green bunching onion in central and southern Vietnam. J. Fac. Agric., Kyushu in Univ., 51: 275-283

Van Alphen, J. J. M. and M. E. Visser 1990 Superparasitism as an adaptive strategy for insect parasitoids. Annu. Rev. Entomol. 35: $59-79$ 
Van Lenteren, L. C. 1981 Host discrimination by parasitoids. In "Semiochemicals", ed. by D. A. Nordlund, R. L. Jones and W. J. Lewis, Wiley, New York, pp. 1-79

Wardlow, L. R. 1985 Control of leafminer on Chrysanthemums and tomatoes by parasites. In "Biological Pest Control: the Glasshouse Experience", Cornell Univ. Press, Ithaca, N.Y., pp. 129-133

Weintraub, P. G. 2001 Effects of cyromazine and abamectin on the leafminer, Liriomyza huidobrensis and its parasitoid,
Diglyphus isaea in potatoes. Crop Prot., 20: 207-213

Weintraub, P. G. and A. R. Horowitz 1998 Effects of translaminar versus conventional insecticides on Liriomyza huidobrensis (Blanchard) (Ditera: Agromyzidae) and Diglyphus isaea Walker (Hymenoptera: Eulophidae) populations in celery. $J$. Econ. Entomol., 91:1180-1185

Weisser, W. W. and A. I. Houston 1993 Host discrimination in parasitic wasps: when is it advantageous? Funct. Ecol., $\mathbf{7}$ $27-39$ 